\title{
THE EFFECTS OF ANAESTHESIA ON EXPERIMENTAL ENDOTOXIN SHOCK*
}

\author{
N. A. RETY, M.sC., M.B.B.S., $\nmid$ AND \\ C. M. Couves, B.A., M.D., F.R.C.s. (EDIN.), F.R.C.S. (c), F.A.C.s.
}

Endotoxin shock is a common and serious disease in man. Endotoxaemia has been widely studied in the dog, and although the syndrome can be reasonably well simulated in this animal, there will always remain some major differences between the responses to endotoxin in man and those in the dog. Although species difference accounts for some of these variations, it is also true that the manner in which endotoxaemia is produced in the dog bears little resemblance to human endotoxaemia. The rapid production of endotoxaemia in the anaesthetized animals is a striking deviation from human endotoxin shock where the endotoxin is released slowly in the fully unanaesthetized state.

There is considerable evidence suggesting that when endotoxin is released from gram-negative bacteria, it acts as a potent sympathomimetic substance. ${ }^{1_{1} 2}$

It has been shown that anaesthetics such as thiopentone will potentiate the vasoconstrictor effects of catecholamines, as well as suppressing capillary flow and causing plethora of the capillary bed. ${ }^{3}$

Used experimentally, the hypoventilation frequently associated with anaesthesia results in reduced elimination of carbon dioxide. Because dioxide is a potent stimulant of the sympatho-adrenal system, catecholamines will be mobilized., ${ }^{8,4}$ It would seem, therefore, that the use of anaesthesia might alter the haemodynamic effects of endotoxin in the experimental animal.

The adverse effect of anaesthesia on the experimental animal in shock is also reported by others. ${ }^{2,5,6}$ Moyer $^{7}$ observed that norepinephrine infusion sufficient to raise the blood pressure by $20 \mathrm{~mm}$. $\mathrm{Hg}$ or more and maintain it at this level will result in the death of the animal in 18 hours if the animal is anaesthetized. No deaths occurred in unanaesthetized animals. For these reasons, it was decided to evaluate the effect of anaesthesia on the endotoxin-shocked animal.

\section{Materiats and Methods}

Twenty-three adult mongrel dogs were subjected to endotoxin shock by the slow intravenous administration of lipopolysaccharide E coli 0111: B4 (Difco) endotoxin, in a dose of $5 \mathrm{mg} . / \mathrm{kg}$. diluted in $250 \mathrm{ml} .5$ per cent dextrose in water.

Fifteen dogs were anaesthetized with intravenous sodium pentobarbital (Abbott), $30 \mathrm{mg} . / \mathrm{kg}$. In this group, sufficient anaesthesia was achieved for the duration of the experiment (five hours).

Eight dogs were subjected to endotoxin in the awake state. A special harness

- From the Surgical-Medical Research Institute and University of Alberta Hospital, Edmonton, Alberta.

† Supported by the Canadian Life Insurance Officers' Association Research Fellowship.

fAssociate Professor of Surgery, University of Alberta, Edmonton, Alberta. 
was employed to support these animals in an upright position. Preparatory cannulations of the arteries and veins in the neck were performed under sodium pentobarbital anaesthesia, $30 \mathrm{mg} . / \mathrm{kg}$. intravenously, on the day prior to the experiment in four dogs, while the other four were prepared under brief thiopental sodium anaesthesia, $25 \mathrm{mg} . / \mathrm{kg}$. intravenously, immediately before the experiment. In the latter group, the dog was transferred to the harness immediately following preparatory surgery. The experiment was not begun until the effects of anaesthesia appeared to have worn off and the dog was fully awake, which was usually after 60 to 90 minutes.

The parameters studied were the blood pressure, central venous pressure, urine output, arterial $\mathrm{pH}, \mathrm{P}_{\mathrm{CO}_{2}}$ and $\mathrm{HCO}_{3}-$. The endotoxin was infused slowly over a two-hour period. The blood pressure was monitored through a polyethylene cannula inserted into the right omocervical artery and connected to a Statham pressure transducer linked with a Sanborn Poly-Viso recorder. Acid-base balance studies were made using the Astrup method. Before and after this experiment, the dogs were housed in the vivarium under the supervision of a veterinary surgeon. Dogs which survived for one week following the experiment were regarded as survivors.

\section{Results and Discussion}

The effect of endotoxin infusion on the mean pressure in the two groups is illustrated in Figure 1. The average reading in both groups is virtually identical

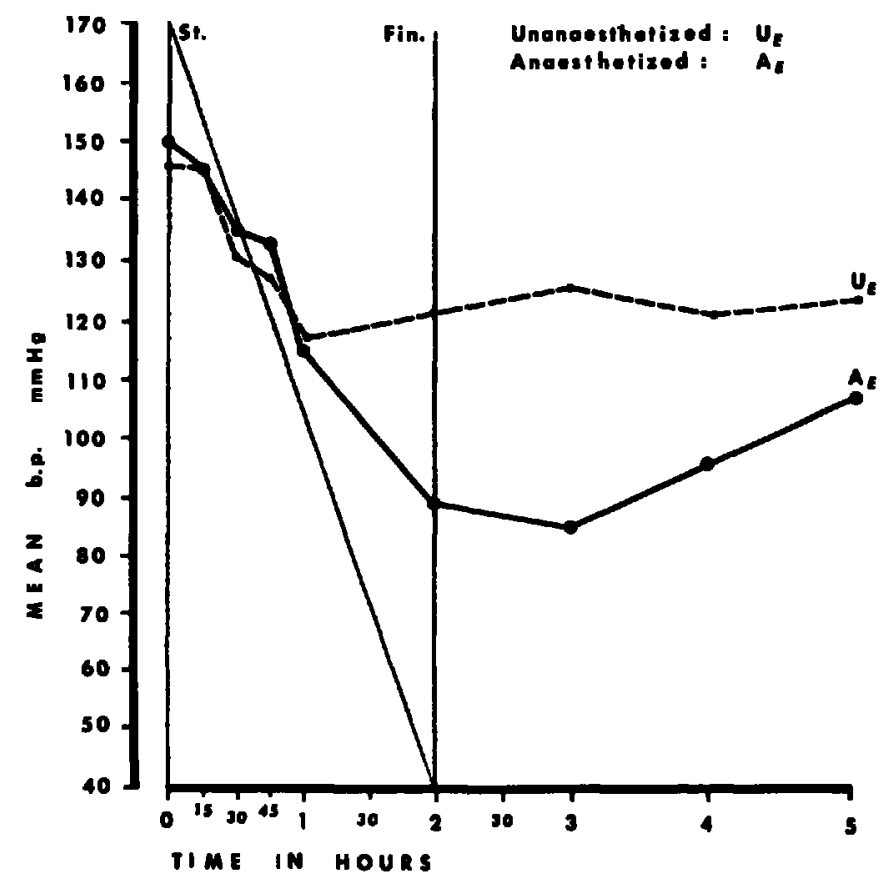

Figure 1. Mean blood pressure changes in anaesthetized and unanaesthetized dogs during and after two-hour endotoxin infusion. 


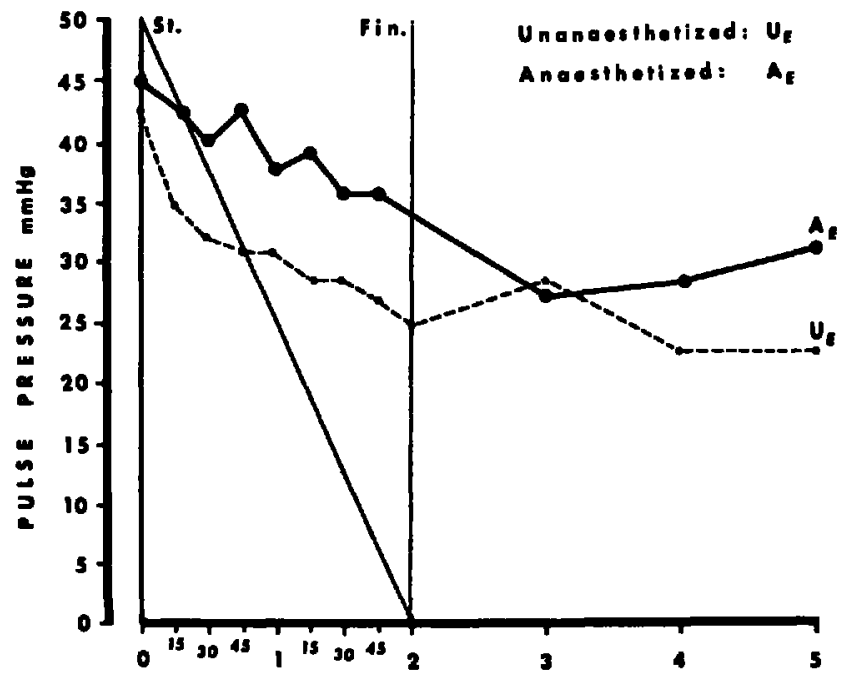

IIME IN HOURS

Figure 2. Changes in pulse pressure.

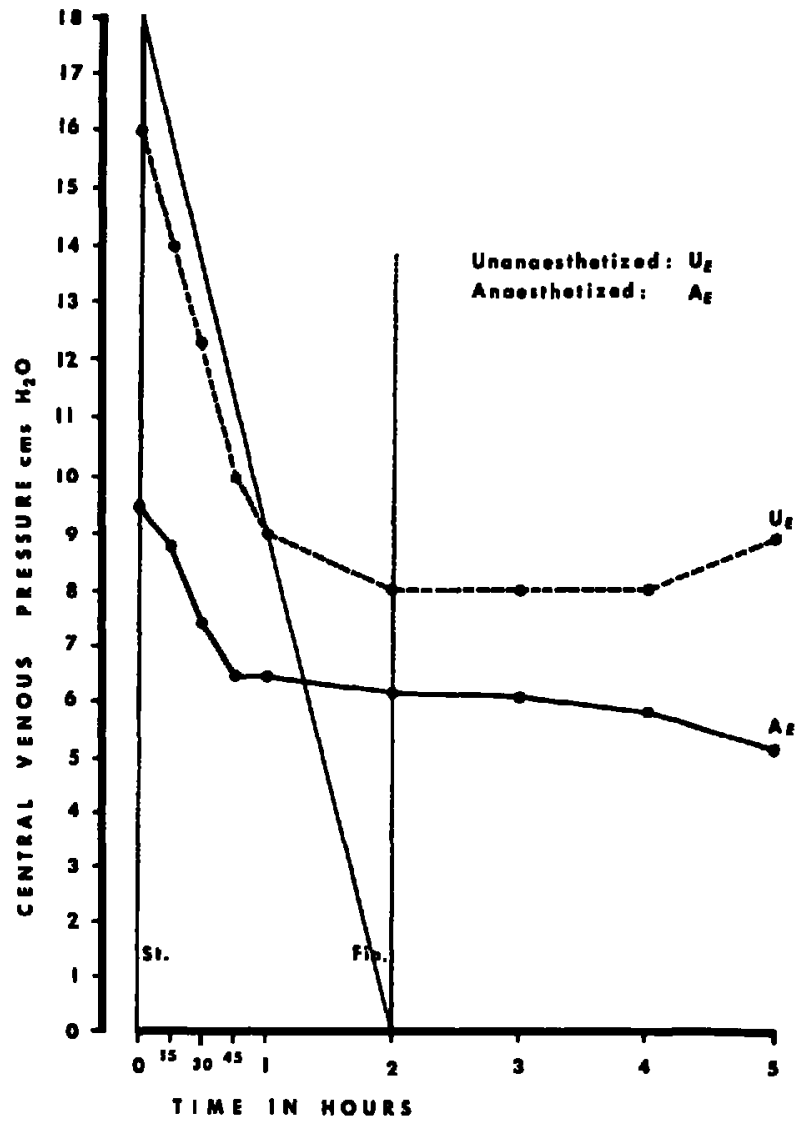

Figure 3. Changes in central venous pressure. 
at the beginning of the experiment. Deterioration occurred equally in the first hour of the infusion in both groups. Thereafter, the blood pressure in the anaesthetized group continued to fall, while it remained stable in the unanaesthetized dogs. At three hours, the difference in the two groups was statistically significant at the $p<0.05$ level. This would suggest that anaesthesia at this point in the experiment enhanced the sympathomimetic effect of endotoxin in the anaesthetized group. In the subsequent two hours, however, some degree of compensation was achieved in the anaesthetized animals and the blood pressure rose to a level approximating that in the unanaesthetized group. At five hours, there was no significant difference in the mean blood pressure level between the two groups. There was no significant difference in the pulse pressure between the two groups as a result of endotoxin administration (Fig. 2).

The central venous pressure exhibited a more profound fall in the unanaesthetized group during the first hour of endotoxin infusion. This may have been due to hyperpnoea typical of the group during this period. Parallel readings were shown after the first hour in the two groups (Fig. 3).

The anaesthetized group showed a higher arterial $\mathrm{P}_{\mathrm{CO}_{2}}$ level (Fig. 4) and a lower arterial pH (Fig. 5) at the start of the experiment. This is probably related to hypoventilation during anaesthesia. At the end of five hours, $\mathrm{P}_{\mathrm{CO}_{2}}$ and $\mathrm{pH}$ levels in the two groups were virtually identical.

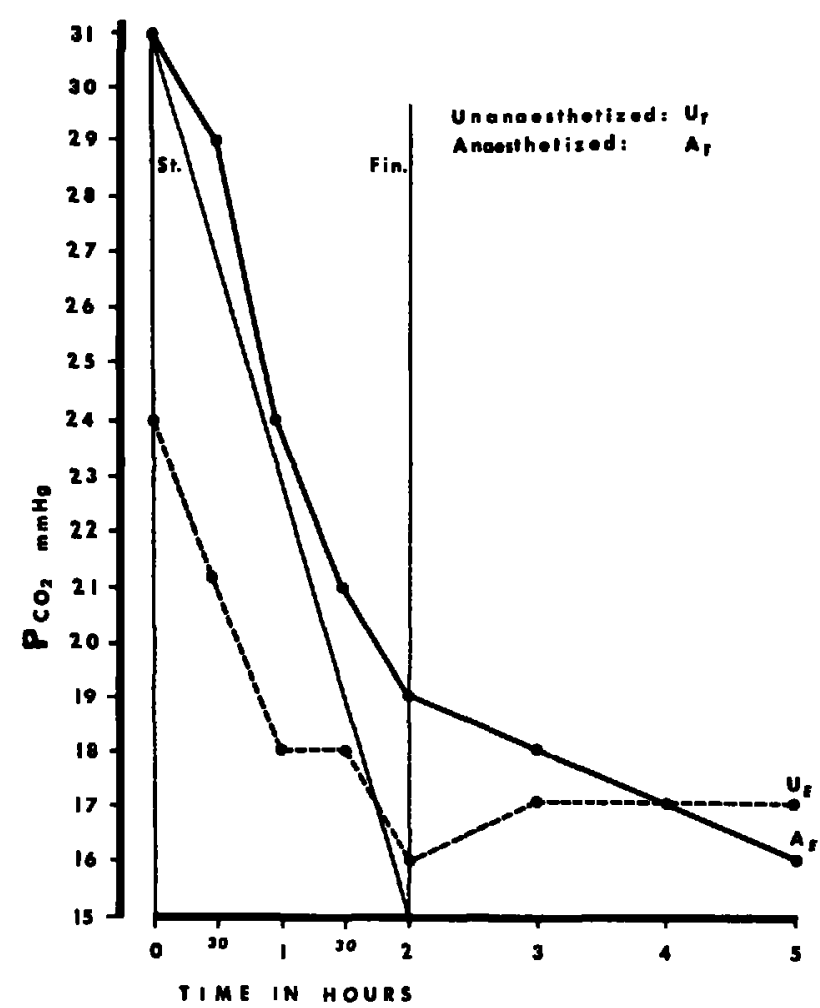

Figure 4. Changes in carbon dioxide tension. 


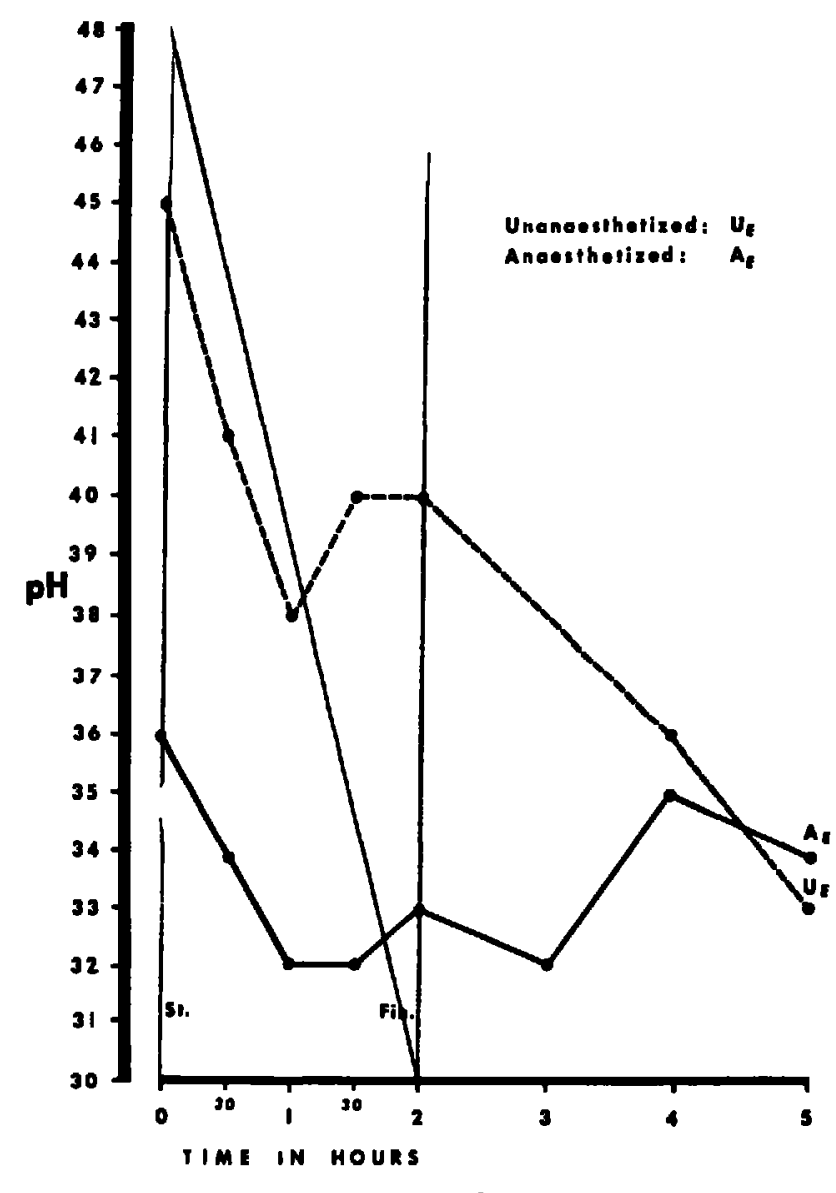

Figure 5. pH changes.

The $\mathrm{HCO}_{3}$ - level in the two groups remained closely parallel in both anaesthetized and unanaesthetized dogs during the five hours of measurement (Fig. 6).

In the unanaesthetized group, three dogs were long-term survivors and the remaining five died within 5.4 to 120 hours from the start of the experiment. Among the anaesthetized dogs, five out of fifteen survived. Death in the other dogs took place in 6.5 to 120 hours.

The experiment on the unanaesthetized dogs had several undesirable features. Some dogs did not tolerate the harness well. The animal's frustration and the hyperventilation which was observed in these experiments may have introduced unnecessary variables. Dependent oedema in the paws was another constant feature of this experiment. These factors were controlled to some extent in the group which was prepared with short thiopental anaesthesia before the experiment.

However, despite improvement in the method of preparation, the unanaesthetized experiment is still inferior to that conducted under anaesthesia. Under anaesthesia, the dogs were stable and were not influenced by their environment. In the anaesthetized dog, a larger number of parameters can be measured. 


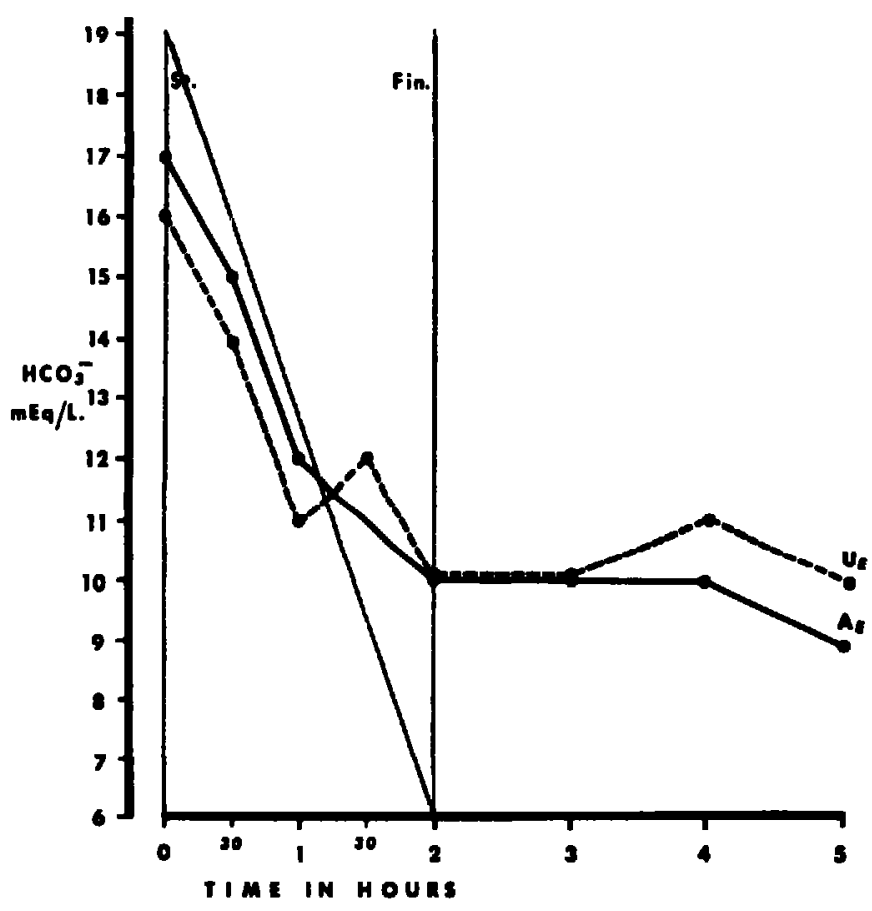

FrG. 6. $\mathrm{HCO}_{3}$ - changes.

Consideration of these facts leads one to the conclusion that there is no advantage in the study of endotoxin shock in the unanaesthetized dog. Anaesthesia affords a more elegant experiment and should be used in preference.

\section{Summary and Conclusions}

Twenty-three healthy adult dogs were subjected to endotoxin shock to evaluate the effect of anaesthesia on circulatory parameters. Fifteen dogs were anaesthetized, while the remainder were exposed to endotoxin in the awake state. The results obtained indicate that the unanaesthetized animal is able to compensate during the process of circulatory deterioration following endotoxin and is a more rugged, but less reliable, experimental model. Experiments under anaesthesia are easier to perform and yield data which are not biased by the dog's reaction to its environment. The anaesthetized animal is thus more ideally suited for this study.

\section{ACKNOWLEDGMENT}

The technical assistance of Mr. Alexander Geczy is gratefully acknowledged.

\section{REFERENCES}

1. Gounzis, J. T.; Hollengeng, M. W.; \& Nickonnson, M. Involvement of Adrenergic Factors in the Effects of Bacterial Endotoxin. J. Exp. Med. 114: 593 (1961).

2. Lillehei, R. C. \& MacLean, L. D. The Intestinal Factor' in Irteversible Endotoxin Shock. Ann. Surg. 148: 513 (1958). 
3. Price, H. L. General Anesthesia and Circulatory Homeostasis. Physiol. Rev. 40: 187 (1960).

4. Drupps, R. D. Anesthesia and Shock. Fed. Proc. 20: Suppl. 9, 224 ( 1961).

5. Lrumarer, R. C. The Intestinal Factor in Irreversible Hemorrhagic Shock. Surgery. 42: (1957).

6. Scerwenndurg, F., \& Fne, J. Resistance to Bacteria in Hemorrhagic Shock: II. Effect of Transient Vascular Collapse on Sensitivity to Endotoxin. Proc. Soc. Exp. Biol. Med. 88: 589 (1955).

7. Morke, J. H. Panel Discussion: International Symposium on Angiotensin, Sodium and Hypertension. Canad. M. A. J. 90: 334 (1964). 